\title{
Editorial
}

\section{Community informatics in pandemic times}

\section{Colin Rhinesmith}

\author{
Editor-in-Chief, The Journal of Community \\ Informatics \\ crhinesmith@simmons.edu
}

In my last Editorial, I introduced myself to this community as the new Editor-in-Chief and honored the work that many had contributed to help steward this journal through challenging times. One year later, since the last issue was published, I am excited to announce a new addition to the leadership of The Journal of Community Informatics (JoCI). Dr. Peter Johnson, Associate Professor in the Department of Geography and Environmental Management at the University of Waterloo will be joining me as CoEditor-in-Chief.

Peter has already proven to be a strong partner and champion for this journal. He played a critical role in helping to move JoCI to its new stable home in the University of Waterloo Libraries. He has also dedicated many hours of his time helping to make important decisions about how best to manage and lead this journal. I am grateful for his time and leadership and look forward to working with Peter as Co-Editors-in-Chief.

This new co-leadership model has encouraged us to consider several new ideas, which I will use this space below to elaborate upon.

1. Institutionalizing the Co-Editor-in-Chief model for JoCI. There are several benefits to having a permanent co-editorship model, some of which I've already mentioned above. In addition, I believe this model will be helpful to ensure that whoever leads the journal into the future has plenty of support, particularly as JoCI remains an all-volunteer effort, at least for now.

2. Growing and rotating the editorial team. While I continue to be grateful to our Associate Editors, Tom Denison and Eduardo Villanueva-Mansilla, there is still room to grow the journal's leadership team. We would like to invite others who are interested to join the JoCI associate editor team. Peter and I have discussed establishing a leadership arrangement where associate editors and editors-inchief would rotate roles over a 2-3-year period. This could allow for new ideas and perspectives to enter JoCI leadership, and to respect the individual personal and professional constraints that inevitably arise. These are just some of the new ideas that we are considering. 
3. Publishing individual articles when they are ready as an online first model. Peter and I have discussed this idea in the past and are now ready to move forward with this model for JoCI. In 2022, we will begin publishing individual articles on the website when they are ready to be published. Future issues will be published when there are enough individual articles to be included in a full issue (typically 6-10 articles), or if there is a special issue on the same theme to be published at one time. We look forward to piloting this new publishing model in the coming year.

As mentioned above, it has been one year since the last issue of The Journal of Community Informatics was published. In this time, close to four million more people worldwide have died due to the COVID-19 pandemic, bringing the total number of deaths up to 5,200,267 and a total number of $260,867,001$ cases confirmed at the time this Editorial was written. ${ }^{1}$ As new variants of the Coronavirus disease continue to emerge, the race to vaccinate the world's population against this deadly virus remains an enormous challenge, which in turn has deepened existing social inequalities.

This reality of the global pandemic is critically important to mention within the context of community informatics. While we celebrate this new issue of JoCI and its ability to persevere during this time of crisis, we must also recognize the magnitude of loss and mourning experienced worldwide. It is within this context that we might consider the words published in this issue as part of a broader human effort to promote healing and care.

\footnotetext{
${ }^{1}$ https://www.who.int/emergencies/diseases/novel-coronavirus-2019
} 